\title{
Journey of a Research Article
}

\author{
Suvarna Satish Khadilkar ${ }^{1,2}$
}

Received: 9 March 2018/Accepted: 9 March 2018/Published online: 27 March 2018

(C) Federation of Obstetric \& Gynecological Societies of India 2018

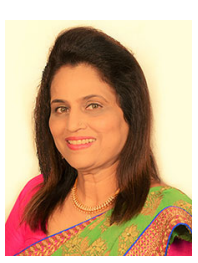

About the Author

Dr. Mrs. Suvarna Satish Khadilkar is the Editor-in-chief of this journal. She is currently working as Consultant GyneEndocrinologist, Bombay Hospital Institute of Medical Sciences and Medical Research Centre, Mumbai. In the past she worked as Associate Professor and Unit Chief at JJ Group of Hospitals and Grant Medical College [GMC], Mumbai, and thereafter in the capacity of the Professor and Head in Department of Obstetrics and Gynecology, Government Medical College, Kolhapur, Maharashtra. She has been an undergraduate and postgraduate teacher and examiner, Mumbai University and Maharashtra University of Health Sciences. Pursuing her interest in endocrinology, she acquired Diploma in Endocrinology from the prestigious University of South Wales, UK, and has been appointed as a recognized teacher in endocrinology in University of South Wales. She is the Treasurer of FOGSI. She has held many prestigious positions like Chairperson of Reproductive Endocrinology Committee of FOGSI, President, Association of Medical Women in India, Mumbai. She has been National President of Indian Menopause Society and she is the Clinical Secretary of MOGS. She has published six text books and more than 70 articles at national and international levels. She is recipient of 30 awards for her research work including the Young Scientist Award.
\end{abstract}

Prof Suvarna Khadilkar MD DGO FICOG, CIMP, Diploma in Endocrinology (UK) is Editor in Chief of Journal of Obstetrics and Gynecology of India, and Treasurer, FOGSI, she is Consultant Gyneendocrinologist, Bombay Hospital \& Medical Research Centre, Mumbai, Former Professor and Head, Dept of ObGyn, RCSM, Government Medical College, Maharashtra and Asso. Prof. \& Unit Chief Grant Medical College and Cama \& Albless hospital, Mumbai.

Suvarna Satish Khadilkar suvarnakhadilkar@yahoo.com; suvarnakhadilkar2@gmail.com

1 PG Diploma in Endocrinology, Mumbai, India

2 Mumbai, India
This editorial will take you through the journey of an article, help you understand how it goes through various phases before it is published and what happens to the article after it is published. I hope this enlightens the readers and authors about a transparent editorial process. I am sure this will generate interest in conducting good quality research. A lot of hard work and rigorous processing is involved before the manuscript sees the light of the day.

A hypothesis is born out of years of experience, observations and evidence in the literature. Thus, original research is initiated. It is undertaken by a team with principal investigator as the lead, or the first author. After completion of the research, it is usually presented to scientific community for the critical inputs.

All the co-authors actively contribute towards making of the manuscript. Changes are done as per their suggestions, 
and final draft is approved by all. The necessary permissions have been taken, ethical committee clearance is obtained and the article is ready to be submitted. The antepartum phase... so to say is complete.

It is extremely important for the author to search for a suitable journal. If it boards on to a wrong train, the journey will end prematurely, and it may not reach its destination. It pays to spend time to browse through issues of available journals in the subject of interest, to decide on the right path, or right journal. The best journal perhaps is the one which is inclined to publish manuscripts of similar categories, for example, clinical, experimental, basic sciences, etc. It is also important to make sure that manuscripts on similar issues have not been recently published by the target journal. Authors should first take the role of the reader and read their own article and be the critique of their own article and make unbiased comments. Consider what a reader would want and also study the journal style in details. No author can be perfect, and the article written by him may have many errors, which can be corrected after this self-assessment. Now the article is ready for submission.

Submission process can be tedious for the uninitiated as various journals follow various platforms and submission methods, some allow 'your style' and others are much rule bound. Some require audio slides and messages, and so on. The covering letter is also important as it gives the importance of the subject and the purpose of the authors' efforts which helps the editor decide on it.

We obstetricians know that the most difficult journey of life is through the birth canal!! This intrapartum journey of the article begins on board of journal editorial software! The article is assessed by an editor. The editor will initially read the covering letter and the abstract and then main body of that article to get an idea of what the manuscript is about. Article goes through the editorial consultation. The editorial consensus will decide further journey of the article. If considered unsuitable, out of scope of the journal, the article is immediately rejected and journey ends right here. Articles of reasonable quality if are found unsuitable for publication in the journal, such articles undergo a diversion of the route of their journey to another track. The editor may decide to transfer it to more suitable journal on the transfer desk of the submission system with authors' permission. These decisions are usually quick and ensure that authors do not loose time. So authors should not feel disappointed by this as it may be accepted in another journal.

Favourable view by the editor results in the manuscript getting peer reviewed. If editor feels the article is of a good quality and is suitable for the journal, he will assign this article to external peer reviewers who are experts in the field. The peer reviewers critically analyse, suggest revisions and give recommendation regarding its further journey; most journals have an absolutely fair system in place. Double-blind process is considered most fair, wherein the reviewer does not have access to author's name and other details and the author cannot have the access to reviewer details!

The peer reviewers are given an objective assessment scale and also a column for comments as subjective assessment. Manuscripts may score high in some sections and low on the others, affecting the total score. The authors need to appreciate that while their manuscripts may be scientifically valuable, they may not be most relevant or appropriate in the broad context and hence may not make the grades. Once the article has been assessed, it goes back to the authors for revision or modification. If revisions done by authors as suggested by editors and reviewers are not found satisfactory, then the article may be rejected at this stage. In case of differences of opinions, Editor-in-Chief's opinion is the final one. If the changes are up to the mark, it goes through thorough checking and is now ready for acceptance to publish. After sending the letter of recommendation to the author, the accepted articles are now taken up by production team. The copy editing and type setting are done as per journal style. Article will be sent to the author for proof reading. Proof reading is the last time the author will get to make any changes, though limited to only technical changes at this stage. After thorough proof reading, to the satisfaction of an author, it is published online. In the current times, the online first systems bring the completed manuscript with a DOI (Digital Object Identifier), a unique number in the ahead of print format. This is a very effective system which allows the authors to quote and use the article before it finds an issue. The article will be accessible globally after it is published online. Once an article is assigned to an issue, it reaches its final destination. The most difficult journey through the editorial process comes to an end. Print versions can take time depending upon the frequency of the journal issues. After a few years, the article loses its value; however, it may be of interest to some researchers in coming years; hence, they are best archived.

Thus, an article goes through an arduous journey starting from stage of conception, delivery, newly born stage, adolescence and finally to senescence, when it is archived!!! Happy publishing!! 